\title{
ANALISA ANOMALI GAYABERAT TERHADAP KONDISI TATANAN TEKTONIK ZONA SUBDUKSI SUNDA MEGATHRUST DI SEBELAH BARAT PULAU SUMATERA
}

\author{
Anita Thea Saraswati, Ira Mutiara Anjasmara \\ Jurusan Teknik Geomatika FTSP-ITS, Kampus ITS Sukolilo, Surabaya, 60111 \\ Email : theanitats@gmail.com
}

\begin{abstract}
Abstrak
Aktivitas tektonik yang terjadi di bumi merupakan hal yang masih terus diteliti sampai sekarang. Sumatera yang terletak pada area Sunda Megathrust, yang merupakan zona subduksi Lempeng Indo-Australia dan Lempeng Eurasia, mengakibatkan daerah ini rentan dengan aktivitas seismogenic. Salah satu akibat dari adanya pergerakan kedua lempeng ini adalah terbentuknya tatanan tektonik di wilayah Sumatera. GOCE (Gravity field and steady-state Ocean Circulation Explorer) menawarkan metode yang cepat dengan cakupan global untuk mendapatkan data gayaberat bumi. Dengan memanfaatkan hitungan dari spherical harmonic coeffisien (SHC) serta dilengkapi dengan data Digital Elevation Model (DEM), dapat diketahui nilai anomali gayaberat pada suatu wilayah. Distribusi anomali gayaberat mampu mencerminkan kondisi tektonik di suatu area. Variasi spasial dari anomali gayaberat menunjukkan bahwa pada palung yang terbentuk akibat subduksi kedua lempeng memiliki nilai anomali gayaberat negatif dengan nilai rata-rata sebesar -42.8729 mgal. Forearc ridge yang terbentuk akibat konvergensi lempeng memiliki nilai anomali gayaberat positif, sedangkan forearc basin yang merupakan cekungan diantara backarc dan forearc ridge, memiliki nilai anomali gayaberat negatif yang lebih kuat daripada yang terdapat pada Sunda Megathrust. Variasi temporal yang teramati menunjukkan bahwa distribusi anomali gayaberat positif yang terdapat pada prisma akresi di kedua tepian palung bergerak semakin mendekati Sunda Megathrust pada tiap seri pengamatannya, sedangkan distribusi anomali gayaberat negatif pada palung laut dan forearc basin membentuk suatu pola distribusi yang semakin menyempit sehingga menyebabkan semakin curamnya gradient anomali gayaberat pada area di sekitarnya.
\end{abstract}

Kata Kunci : Anomali gayaberat, GOCE, Sunda Megathrust, Zona subduksi

\section{PENDAHULUAN}

\section{Latar Belakang}

Indonesia merupakan sebuah negara yang terletak di antara 3 lempeng tektonik aktif, yaitu Lempeng Indo-Australia, Lempeng Eurasia dan Lempeng Pasifik. Zona pertemuan antar lempeng tektonik disebut dengan zona subduksi (Sieh, 2007). Ketiga lempeng ini senantiasa bergerak dengan arah dan kecepatan yang berbeda-beda. Hal inilah yang menyebabkan terjadinya penunjaman lempeng di lokasi pertemuan antar lempeng tersebut, yang disebut juga dengan megathrust.

Sunda Megathrust merupakan tunjaman yang terletak pada zona subduksi Lempeng IndoAustralia dengan Lempeng Eurasia. Sunda Megathrust terletak mulai dari selatan Bangladesh, melingkar di sepanjang barat dan selatan Sumatra, Jawa, Bali dan sebelah timur Indonesia hingga barat laut Australia - semuanya sepanjang kira-kira 5500 km (Sieh, 2007).
Memiliki area pengamatan yang luas, presisi, resolusi spasial dan tingkat resolusi spektral yang tinggi, serta tidak terbatas oleh topografi dan transportasi, pengukuran gayaberat dengan satelit adalah sebuah metode efektif untuk mengukur anomali gayaberat dan variasi gayaberat temporal di area gempa, gunung api, dan tsunami. Prinsip dari satelit gayaberat adalah perturbasi orbit satelit yang disebabkan oleh adanya medan gayaberat yang diukur menggunakan sensor gayaberat seperti accelerometer, pengukuran jarak teliti dan gravity gradiometer.

Data dari satelit gayaberat mampu memberikan informasi mengenai atmosfer, hidrosfer, lempeng, mantel dan centrosfer bumi di bawah orbit satelit. GOCE (Gravity field and steady-state Ocean Circulation Explorer) adalah satelit gayaberat yang diluncurkan oleh ESA (European Space Agency) pada 17 Maret 2009 lalu dan mampu mengukur gradien gayaberat menggunakan gradiometer 3 sumbu dan memiliki ketelitian hingga 1 mgal dan resolusi spasial kurang dari 100 km (ESA, 2010). 
Dengan adanya pengamatan gayaberat secara kontinyu pada Sunda Megathrust, diharapkan nantinya dapat diketahui variasi spasial anomali gayaberat pada zona subduksi Sunda Megathrust dan kaitannya terhadap tatanan tektonik pada area tersebut sehingga dapat dimanfaatkan menjadi suatu dasar bagi tindakan penanggulangan dan mitigasi bencana yang mengancam pesisir barat Pulau Sumatera. Pemanfaatan data satelit GOCE ini diharapkan juga dapat menjadi suatu metode yang lebih efektif bagi pemantauan aktivitas tektonik di wilayah Indonesia.

\section{METODOLOGI PENELITIAN}

\section{Lokasi Penelitian}

Area studi pada penelitian kali ini adalah pada zona subduksi Sumatera yang berada di sepanjang Sunda Megathrust di sebelah barat Pulau Sumatera. Area studi ini terletak di posisi geografis $18^{\circ} \mathrm{LU}-10^{\circ} \mathrm{LS}$ dan $85^{\circ} \mathrm{BT}-110^{\circ} \mathrm{BT}$.

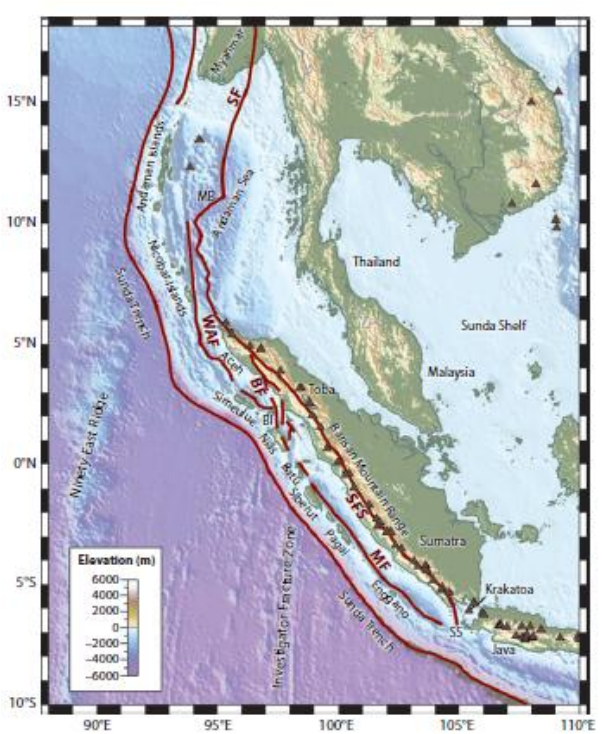

Gambar 1. Lokasi Penelitian (McCaffrey, 2009)

\section{Data}

Data yang digunakan meliputi data spherical harmonic coefficient (SHC) satelit GOCE dengan teknik pemrosesan time-wise solution (GOCE_TIM) yang terdiri dari empat rentang waktu pengamatan dan Digital Elevation Model (DEM) ACE2 untuk menghitung nilai anomali gayaberat di lokasi penelitian. EIGEN-6C2 digunakan juga sebagai referensi pembanding untuk hasil penghitungan data GOCE.
Data bathimetri ETOPO1 dan data patahan digunakan sebagai data pendukung untuk dilakukannya analisa.

\section{Pengolahan Data}

Dalam pemrosesan keempat series data GOCE, digunakan software pengolahan GUT (GOCE User Toolbox) untuk menghitung nilai anomali gayaberat, yang selanjutnya digunakan sebagai data dasar untuk melakukan analisa distribusi anomali gayaberat di lokasi studi. Pada penelitian ini, fungsi perhitungan yang digunakan adalah fungsi perhitungan anomali gayaberat dari data SHC (Heiskanen \& Moritz, 1967; Torge, 2001). Spacing grid yang digunakan dalam perhitungan sebesar $0,02^{\circ}$. Referensi ellipsoid yang digunakan pada penelitian ini menggunakan datum GRS80 (Geodetic Reference System 1980). Dalam penghitungan anomali gayaberat dari data SHC, rumus yang digunakan adalah (Heiskanen \& Moritz, 1967):

$$
\begin{array}{r}
\Delta g(r, \theta, \lambda)=\frac{G M^{R E F}}{r^{2}} \sum_{n=0}^{N_{\max }}(n-1)\left(\frac{a^{R E F}}{r}\right)^{n} \sum_{m=0}^{n}\left(\Delta \bar{C}_{n m} \cos m \lambda\right. \\
\left.+\Delta \bar{S}_{n m} \sin m \lambda\right) \bar{P}_{n m}(\cos \theta)
\end{array}
$$

Keterangan :

$$
\begin{aligned}
& \Delta g \quad=\text { anomali gayaberat di titik } \\
& G M=\text { konstanta gravitasi dikalikan } \\
& \text { dengan total massa bumi } \\
& a=\text { radius ekuatorial dari ellipsoid bumi } \\
& n=\text { degree } \mathrm{SHC} \\
& N_{\max }=\text { degree } \text { maksimal dari SHC } \\
& m \quad=\text { order dari SHC } \\
& r=\text { jarak radial titik pengamatan dari }
\end{aligned}
$$




$$
\begin{aligned}
\Delta \bar{C}_{n m}, \Delta \bar{S}_{n m} & =\text { koefisien residual dari SHC } \\
& \text { setelah mengurangkan koefisien } \\
& \text { potensial normal dari potensial } \\
& \text { gravitasi }
\end{aligned}
$$

\section{Tahap Validasi dan Uji Perbandingan}

Untuk menguji nilai anomali gayaberat hasil perhitungan dari data GOCE, digunakan data EIGEN-6C2, yang merupakan model gayaberat bumi yang memiliki ketelitian data lebih tinggi (ICDC, 2013).

\section{Tahap Pengolahan Data Patahan dan Titik Gempa}

Data patahan yang digunakan diperoleh dari BNPB (Badan Nasional Penanggulangan Bencana) dan beberapa sumber lainnya. Data yang diperoleh belum sesuai dengan format data GMT (Graphic Mapping Tool), sehingga perlu dilakukan pemrosesan lebih lanjut agar data sesuai untuk digunakan. Sedangkan data epicenter gempa diperoleh dari United States Geological Survey (USGS). Data yang digunakan dibatasi pada data kejadian gempa dengan magnitudo $>5$. Data kejadian gempa kemudian diproses agar dapat digunakan lebih lanjut pada proses pengeplotan.

Pengolahan data ini meliputi penyeleksian data, sehingga data patahan dan kejadian gempa sesuai dengan lokasi studi dan rentang data pengamatan pada data SHC GOCE. Setelah data diseleksi, lalu dilakukan normalisasi data agar data compatible terhadap masing-masing data GOCE_TIM.

\section{Tahap Penggambaran}

Nilai anomali gayaberat yang didapat dari pemrosesan masing-masing data GOCE diplot menjadi empat buah model. Lalu masing-masing model dibandingkan untuk mengetahui perubahan pola persebaran antar masing-masing rentang waktu pengamatan.

Untuk menganalisa variasi spasial distribusi anomali gayaberat terhadap lokasi patahan dan titik gempa, dilakukan overlay dari data yang ada. Penggambaran bathimetri juga dilakukan demi mendukung analisa yang lebih baik.

Untuk menganalisa variasi temporalnya, dipilih beberapa area untuk dibuat profil cross-section di sepanjang Sunda Megathrust. Selain itu juga dilakukan pengeplotan nilai anomali gayaberat pada beberapa titik sampel dimana terdapat kejadian gempa dengan magnitudo yang cukup besar. Diagram Alir proses Pengolahan Data pada penelitian ini ditunjukkan oleh Gambar 2.

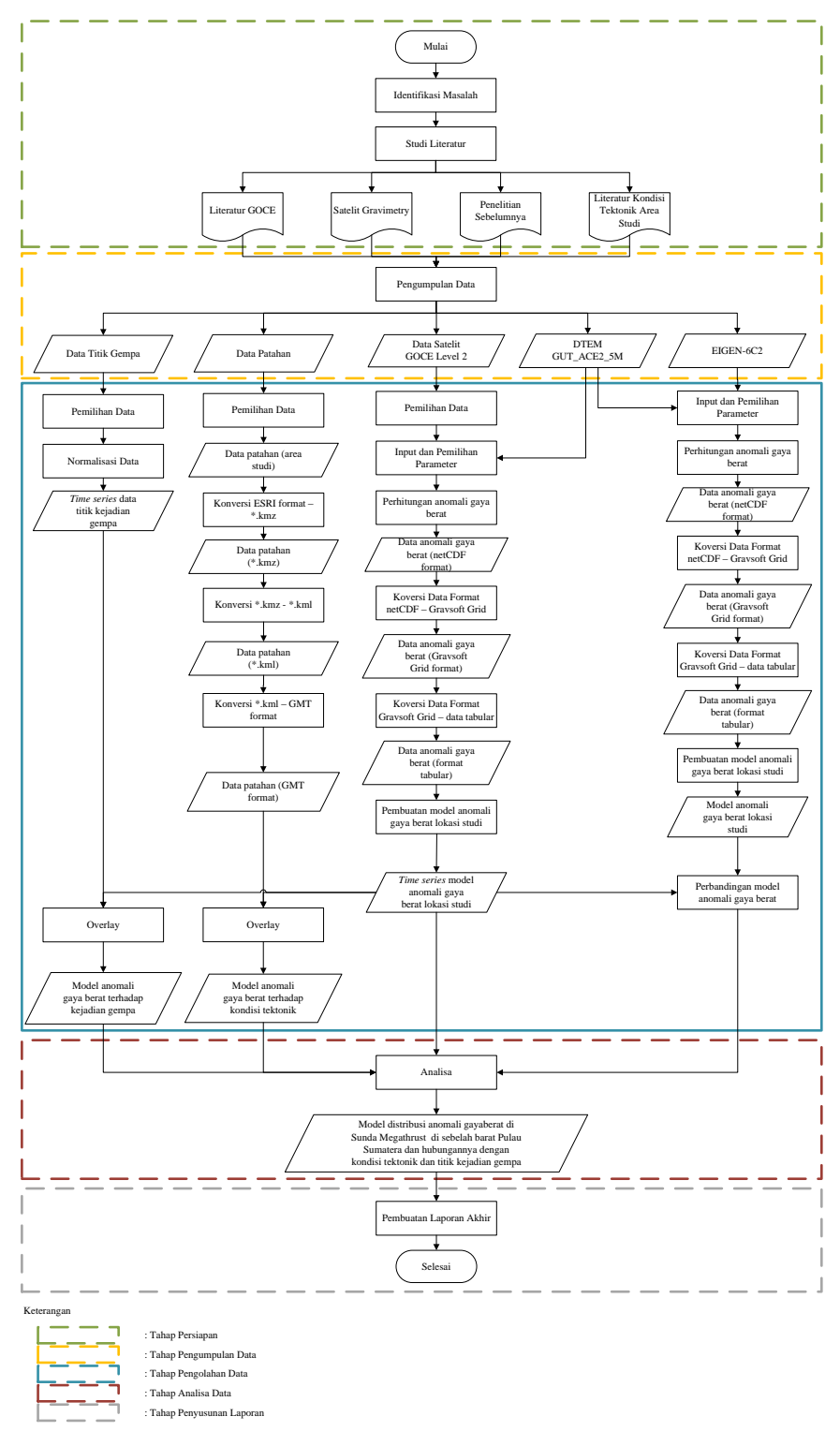

Gambar 2. Diagram Alir Penelitian

\section{HASIL DAN PEMBAHASAN}

\section{Hasil Perhitungan Data GOCE}

Data spherical harmonic yang telah didapatkan kemudian diolah untuk dihitung nilai anomali gayaberatnya. Perhitungan dilakukan dengan menggunakan nilai grid $(\Delta \phi, \Delta \lambda)$ sebesar $0,02^{\circ}$ hingga degree/order 250. Anomali gayaberat yang dihitung merupakan free air anomaly (FAA). Dari 
hasil perhitungan statistik, didapatkan keterangan statistik dari masing-masing data GOCE_TIM yang tercantum pada Tabel 1. Setelah didapatkan nilai anomali gayaberat di setiap titik grid, maka dilakukan pengeplotan untuk menghasilkan model distribusi nilai anomali gayaberat.

Tabel 1. Hasil Perhitungan Statistik Keempat GOCE_TIM

\begin{tabular}{lcccc}
\hline \multicolumn{1}{c}{ Ket. } & $\begin{array}{c}\text { GOCE_ } \\
\text { TIM1 }\end{array}$ & $\begin{array}{c}\text { GOCE_- } \\
\text { TIM2 }\end{array}$ & $\begin{array}{c}\text { GOCE_- } \\
\text { TIM3 }\end{array}$ & $\begin{array}{c}\text { GOCE_ } \\
\text { TIM4 }\end{array}$ \\
\hline Max. & 185.705 & 194.426 & 198.471 & 201.534 \\
(mgal) & & & & \\
Lokasi & $107.16 \mathrm{E}$ & $107.16 \mathrm{E}$ & $107.14 \mathrm{E}$ & $107.14 \mathrm{E}$ \\
Min. & $-7.12 \mathrm{~N}$ & $-7.14 \mathrm{~N}$ & $-7.14 \mathrm{~N}$ & $-7.16 \mathrm{~N}$ \\
(mgal) & -133.816 & -139.057 & -137.501 & -142.171 \\
& $93.12 \mathrm{E}$ & $105.26 \mathrm{E}$ & $105.26 \mathrm{E}$ & $105.32 \mathrm{E}$ \\
Lokasi & $10.04 \mathrm{~N}$ & $-7.7 \mathrm{~N}$ & $-7.7 \mathrm{~N}$ & $-7.72 \mathrm{~N}$ \\
Rata- & & & & \\
rata & -1.98418 & -1.98984 & -1.98891 & -1.98392 \\
(mgal) & & & & \\
$\begin{array}{l}\text { Varian } \\
\text { Std. Dev } \\
\text { (mgal) }\end{array}$ & 986.901 & 1031.94 & 1042.1 & 1061.64 \\
\hline
\end{tabular}

\section{Validasi Anomali Gayaberat GOCE oleh EIGEN- 6C2}

Seperti dijelaskan pada bagian sebelumnya, validasi dilakukan untuk menguji tingkat kebenaran pemrosesan data GOCE yang bereferensi pada model gayaberat yang lebih teliti, yaitu EIGEN-6C2. Hasil perhitungan statistik dari perbedaan masing-masing series GOCE_TIM dengan EIGEN-6C2 disajikan pada Tabel 2.

Tabel 2. Selisih Nilai Anomali Gayaberat dari Tiap Model GOCE_TIM dengan EIGEN-6C2

\begin{tabular}{|c|c|c|c|c|}
\hline \multirow{2}{*}{ Ket. } & \multicolumn{4}{|c|}{$\triangle$ GOCE_EIGEN } \\
\hline & TIM1 & TIM2 & TIM3 & TIM4 \\
\hline Max. (mgal) & 91.0184 & 84.1858 & 82.3557 & 78.8399 \\
\hline \multirow{2}{*}{ Lokasi } & $106.58 \mathrm{E}$ & 106.6 E & $105.46 \mathrm{E}$ & $105.46 \mathrm{E}$ \\
\hline & $-7.32 \mathrm{~N}$ & $-7.34 \mathrm{~N}$ & $-6.74 \mathrm{~N}$ & $-6.74 \mathrm{~N}$ \\
\hline Min. (mgal) & -91.0089 & -83.4269 & -83.7872 & -79.9248 \\
\hline \multirow{2}{*}{ Lokasi } & $105.76 \mathrm{E}$ & $105.78 \mathrm{E}$ & $105.78 \mathrm{E}$ & $105.78 \mathrm{E}$ \\
\hline & $-7.5 \mathrm{~N}$ & $-7.46 \mathrm{~N}$ & $-7.46 \mathrm{~N}$ & $-7.44 \mathrm{~N}$ \\
\hline $\begin{array}{l}\text { Rata-rata } \\
\text { (mgal) }\end{array}$ & -0.0122748 & -0.00661435 & -0.00754647 & -0.0125326 \\
\hline
\end{tabular}

Untuk melihat besar kecocokannya, dilakukan juga perhitungan coefficient correlation dan pengeplotan scatter plot dari masing-masing series GOCE_TIM dengan EIGEN-6C2. Didapatkan nilai $c$ dari masing-masing seri anomali gayaberat GOCE dengan EIGEN-6C2, yang ditampilkan pada Tabel 3.
Tabel 3. Corelation Coefficient EIGEN-6C2 dengan masing-masing GOCE data series

\begin{tabular}{clc}
\hline & GOCE data series & $c$ \\
\hline & GOCE_TIM1 & 0.91836 \\
EIGEN-6C2 & GOCE_TIM2 & 0.93431 \\
(d/o 360) & GOCE_TIM3 & 0.93947 \\
& GOCE_TIM4 & 0.94684 \\
\hline
\end{tabular}
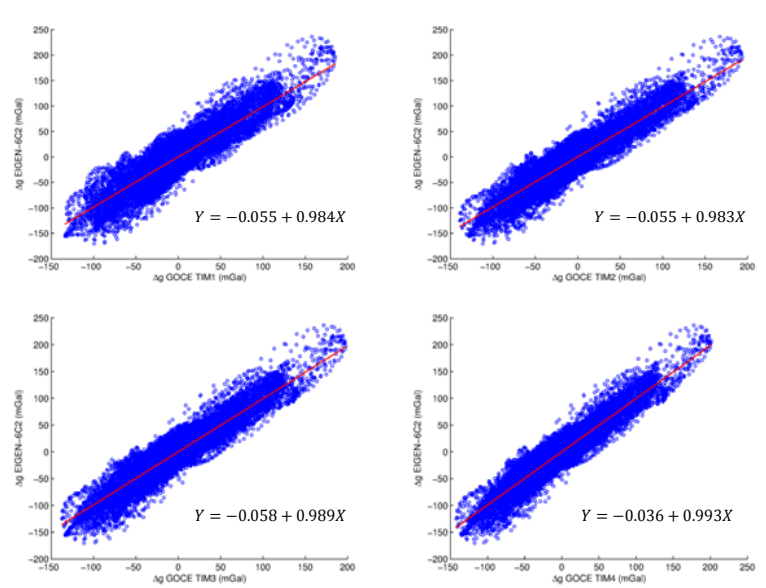

Gambar 3. Scatter Plot $\triangle \mathrm{g}$ EIGEN-6C2 dengan keempat series GOCE

\section{Analisa Variasi Spasial Distribusi Anomali Gayaberat terhadap Zona Subduksi}

Untuk mengetahui variasi spasial dari anomali gayaberat terhadap zona subduksi dari masingmasing seri GOCE_TIM, dilakukan pengeplotan distribusi anomali gayaberat yang dioverlaykan dengan patahan-patahan yang ada di lokasi studi (Gambar 4).

Untuk mendukung proses analisa, dipilih beberapa bagian di sepanjang Sunda Megathrust untuk dibuat profil melintangnya (Gambar 6). Dari gambar tersebut, terlihat bahwa pada Sunda Megathrust, profil anomali gayaberatnya berada pada posisi lembah dan bernilai negatif. Pengecualian terjadi pada section E, yang berada pada Laut Andaman. Hal tersebut tidak berlaku, karena pada area ini terdapat endapan sedimen yang cukup banyak dari Teluk Benggala dan dipengaruhi juga oleh umur dari litosfer samudera yang masih cukup muda (S., 2007; Jarrard, 1986). Nilai anomali gayaberat rata-rata pada Sunda Megathrust menunjukkan nilai negatif dengan nilai $-42,8729$ mgal. Nilai negatif yang lebih kuat justru terjadi pada wilayah di forearc basin, yang merupakan cekungan forearc dengan komposisi batuan endapan sedimen dari kerak benua yang menyusunnya, dimana densitasnya rendah. Selain 
itu, hal ini juga diperkuat dengan adanya adanya pergerakan slab (slab pull) yang mulai berubah sudut menjadi lebih tajam dan mengarah ke bawah yang menyebabkan adanya anomali densitas (S., 2007; Marotta, Spelta, \& Rizzetto, 2006). Nilai anomali gayaberat yang positif berada pada wilayah forearc ridge yang membentuk barisan kepulauan di sebelah barat Pulau Sumatera dan juga pada backarc dan orogen yang membentuk barisan pegunungan di daratan Pulau Sumatera.

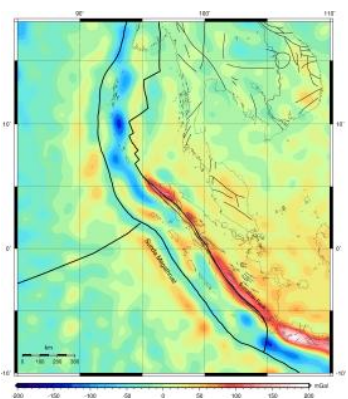

(a) TIM1

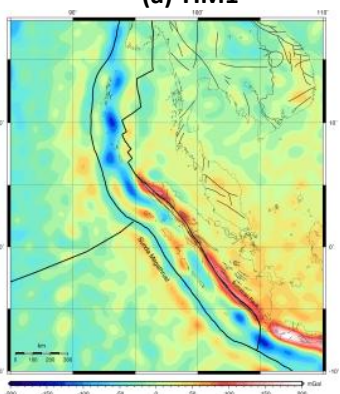

(c) TIM3

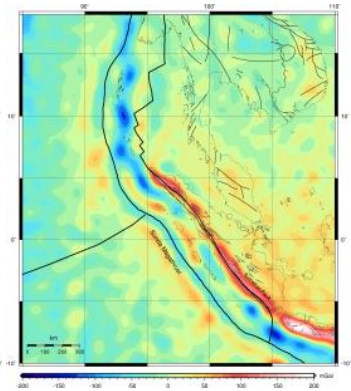

(b) TIM2

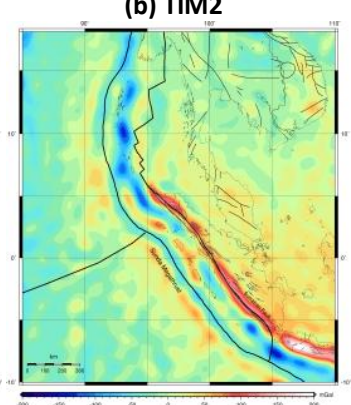

(d) TIM4
Gambar 4. Distribusi $\Delta \mathrm{g}$ dengan Lokasi Patahan di Area Penelitian

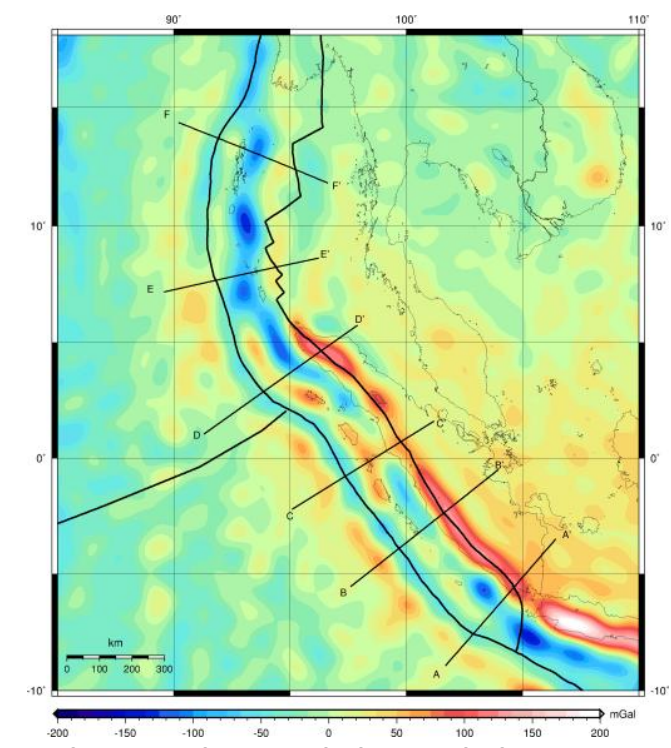

Gambar 5. Lokasi Studi dengan beberapa crosssection
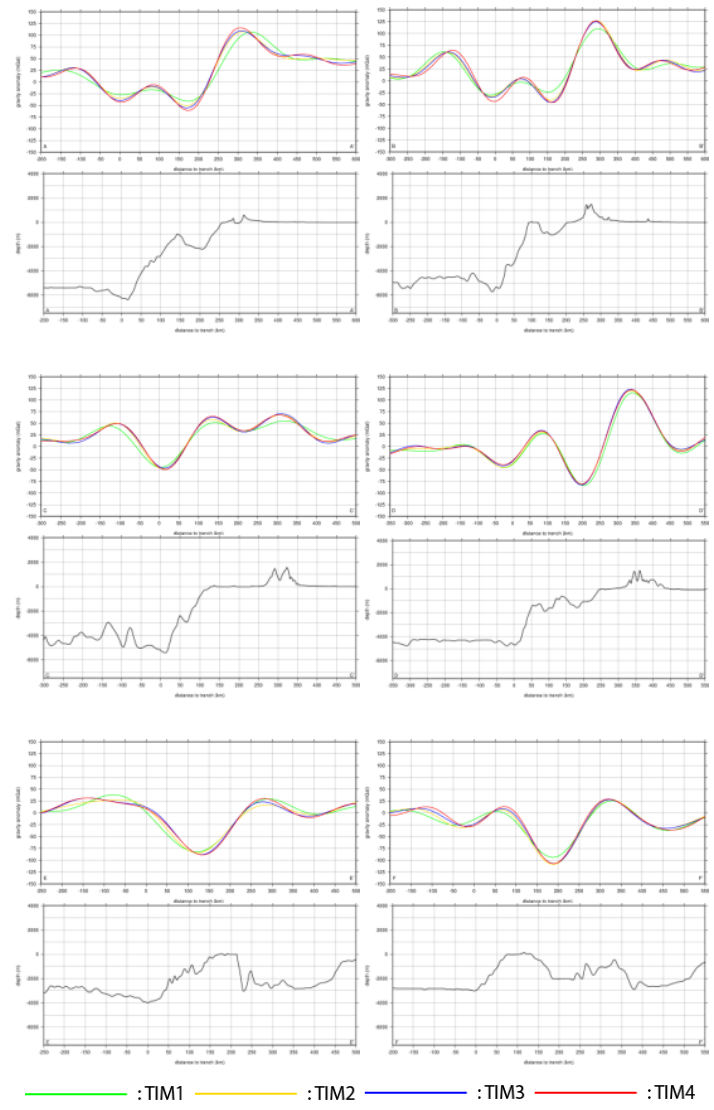

Gambar 6. Profil Melintang Anomali Gayaberat (atas) dan Topografi (bawah) pada Beberapa

Section

Gambar 3 secara umum menunjukkan bahwa pola distribusi anomali gayaberat tidak berubah banyak di tiap serinya. Pada Gambar 6, terlihat bahwa nilai anomali gayaberat pada suatu wilayah berubah pada tiap seri pengamatan. Perubahan yang terjadi berada pada nilai -34 mgal sampai +32 mgal. Selain itu, jika diamati pola pergerakan nilai anomali gayaberat, khususnya Gambar 3 dan Gambar 5, terlihat bahwa pada bagian barat Sunda Megathrust, pada Lempeng Indo-Australia, nilai anomali gayaberat bergerak ke arah timur, mendekati zona subduksi. Hal ini dimungkinkan terjadi karena terjadinya perubahan densitas dari litosfer Lempeng Indo-Australia. Litosfer bumi memiliki daya elastisitas tertentu. Tumbukan Lempeng Indo-Australia terhadap Lempeng Eurasia mampu menyebabkan "pemadatan" litosfer di beberapa lokasi di Lempeng IndoAustralia, sehingga terjadi "penumpukkan" massa. Hal ini menyebabkan terjadinya perubahan densitas litosfer dan menyebabkan terjadinya perubahan nilai anomali gayaberat di lokasi tersebut. Selain itu, disebabkan juga oleh terjadinya perpindahan massa Lempeng Eurasia 
akibat pergerakannya yang mengarah ke timur laut. Pada zona tunjaman Lempeng Indo-Australia dan Eurasia, nilai anomali gayaberat semakin menurun dan sebarannya semakin menyempit. Sedangkan pada bagian timur Sunda Megathrust, pada Lempeng Eurasia, terlihat bahwa nilai anomali gayaberat positif bergerak ke arah barat, semakin mendekat ke arah Sunda Megathrust. Pada forearc ridge, yang berupa gugusan kepulauan di sebelah barat Sumatera, nilai anomali gayaberat meningkat pada tiap seri data pengamatan dengan variasi nilai 3 mgal sampai 35 mgal. Pada forearc basin yang berada di antara gugusan kepulauan dengan Pulau Sumatera, nilai anomali gayaberatnya semakin menurun dengan nilai perubahan sebesar -35 sampai -5 mgal.

\section{PENUTUP}

Berdasarkan penelitian yang telah dilakukan mengenai analisa anomali gayaberat di zona subduksi Sunda Megathrust, kesimpulan yang dapat diambil adalah sebagai berikut:

1. Variasi nilai anomali gayaberat pada zona subduksi Sunda Megathrust berkisar antara 200 sampai 200 mgal. Nilai variasi terkait erat dengan topografi permukaan bumi dan densitas massa bumi akibat aktivitas seismogenic di zona subduksi.

2. Variasi anomali gayaberat pada sekitar patahan Sunda Megathrust yang merupakan zona subduksi lempeng memiliki nilai yang negatif dengan nilai rata-rata sebesar 42,8729 mgal.

3. Variasi temporal anomali gayaberat dari keempat seri data pengamatan memiliki rentang selisih nilai antara -34 mgal sampai +32 mgal. Perubahan nilai anomali gayaberat ini disebabkan oleh beberapa hal, diantaranya adalah perbedaan waktu pengamatan dari masing-masing seri, perbedaan jumlah data pengamatan dari masing-masing seri, serta terjadinya pergeseran lempeng dan aktivitasi tektonik lainnya yang menyebabkan terjadinya perpindahan massa dan perubahan jumlah densitas di suatu area.

4. Distribusi anomali gayaberat pada wilayah di sekitar zona subduksi terkait erat dengan aktivitas tektonik yang ada. Adanya pergerakan lempeng juga ditandai dengan adanya pergerakan pola distribusi anomali gayaberat positif yang bergerak semakin mendekati zona subduksi.

5. Untuk mendapatkan hasil penelitian yang lebih baik, sebaiknya data yang digunakan adalah data temporal dengan jangka waktu pengamatan yang sama dengan rentang waktu pengamatan yang tidak terlalu lama.

\section{DAFTAR PUSTAKA}

ESA. 2010. GOCE Level 2 Product Data Handbook. The European GOCE Gravity Consortium EGGC.

Heiskanen, W. A., \& Moritz, H. 1967. Physical Geodesy. San Fransisco and London: W. H. Freemand and Company.

Heiskanen, W. A., and H. Moritz. 1967. Physical Geodesy. San Fransisco and London: W. H. Freemand and Company.

ICDC. 2013. Geoid EIGEN-6C2. Retrieved 11 13, 2013, from KlimaCampus: http://www.klimacampus.de/

Jarrard, R. 1986. Relations Among Subduction Parameters. Rev. Geophys., 24, 2 , 217284.

Marotta, A. M., Spelta, E., \& Rizzetto, C. 2006. Gravity signature of crustal subduction inferred from numerical modelling. Geophys. J. Int. , 166, 923-938.

McCaffrey, Robert. 2009. "The Tectonic Framework of the Sumatran Subduction Zone." Annu. Rev. Earth Planet. Sci. 2009.37: 345-366.

S., L. 2007. Geodynamics of the Andaman - Sumatra Java Trench-Arc System Based on Gravity and Seismotectonic Study. Kerala: Department of Marine Geology \& Geophysics Cochin University of Science and Technology.

Sieh, K. 2007. The Sunda Megathrust: Past, Present and Future. First International Conference of Aceh and Indian Ocean Studies. Asia Research Institute, National University of Singapore \& Rehabilitation and Construction Executing Agency for Aceh and Nias (BRR), Banda Aceh, Indonesia.

Torge, W. 2001. Geodesy 3 ed. Berlin: de Gruyter. 